\title{
الفقر وتأثيره على المخ
}

\author{
إعداد

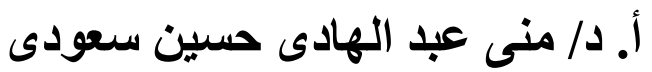

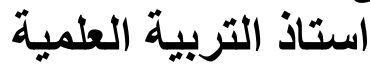 \\ عميد كلية البنات - جامعة عين شمس الأسبة الئق
}




\section{الفقر وتأثيره على المخ}

أ. دا منى عبد الهادى سعودى"

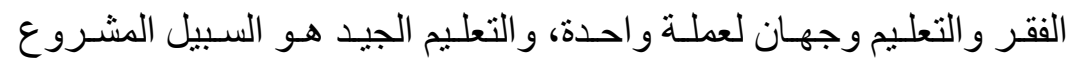

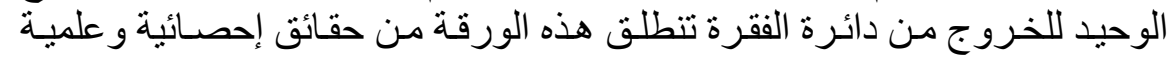
تميعت مع كثرة تداو للها، منها:

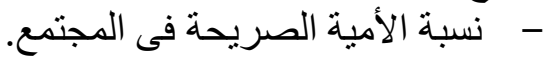

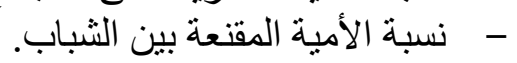

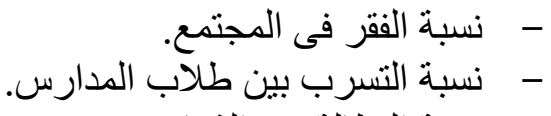

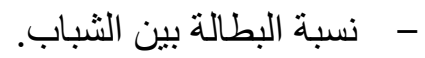

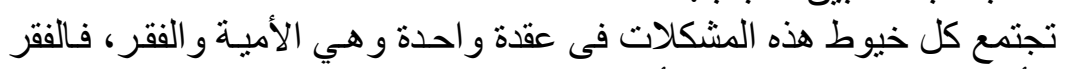

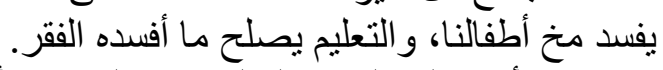

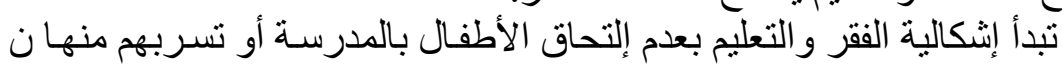

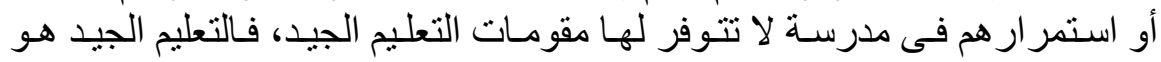

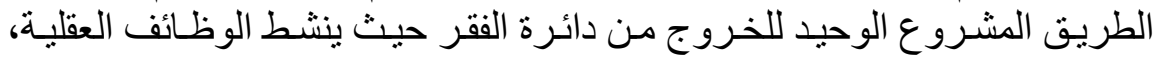

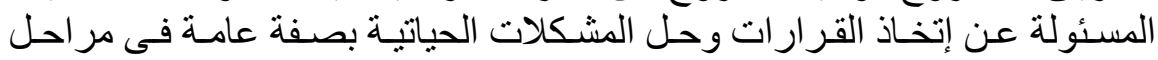

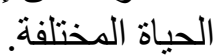

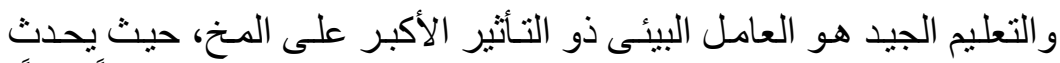

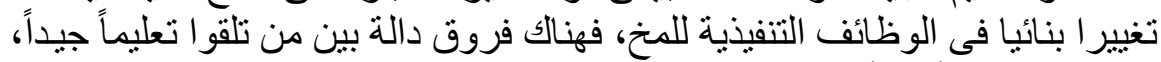

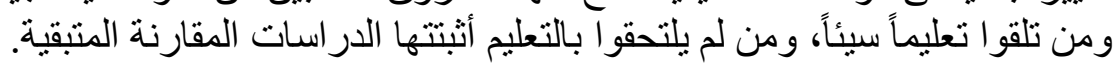

\section{ما المقصود بالققر؟} والسؤال المطروح الآن:

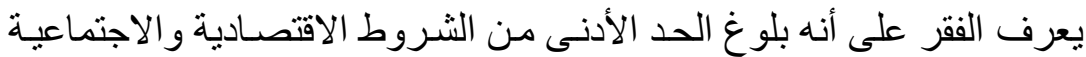

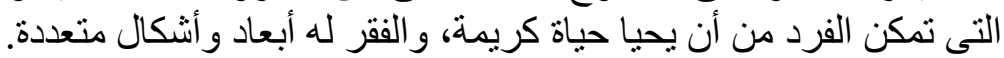

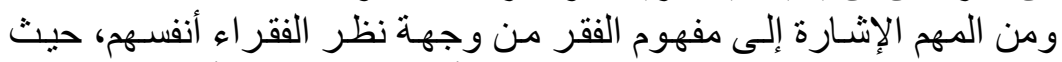

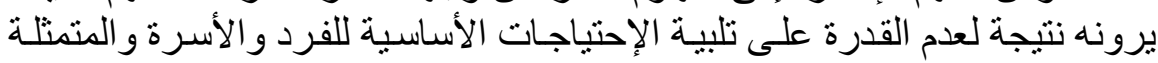

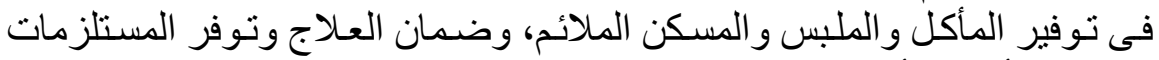

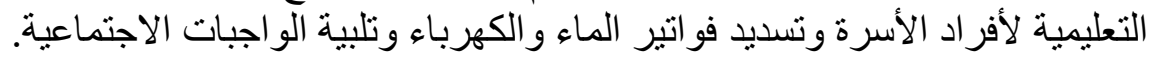

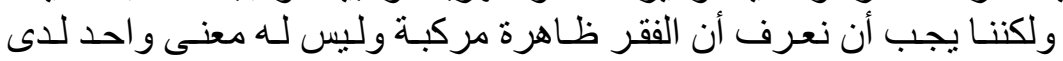

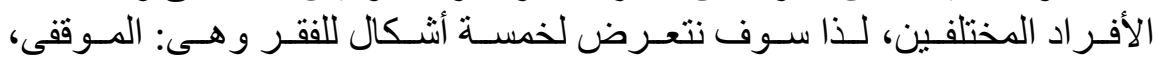

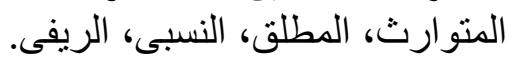

* أستاذ التربية العلمية وعميد كلية البنات - جامعة عين شمس الأسبق

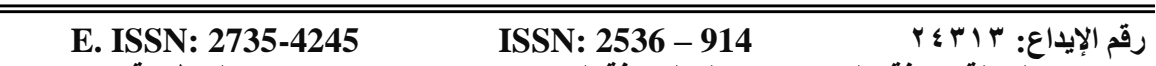

المجلة معرفة علي دوريات بنك المعرفة المصرى، و Edu Search دار المنظومة 
الفقر الموقفى: هو نتيجة لأزمة أو خسارة مفاجئة مثل الكوارث البيئية، الطلاق،

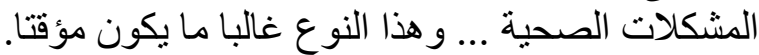

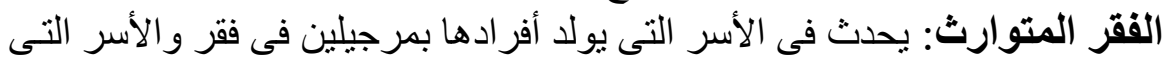

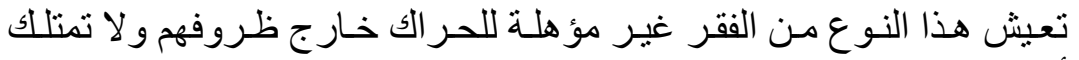

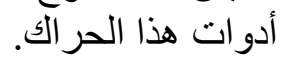

الفقز المطلق: يعنى ندرة الضروريات كالمأوى و الملبس و الغذاء.

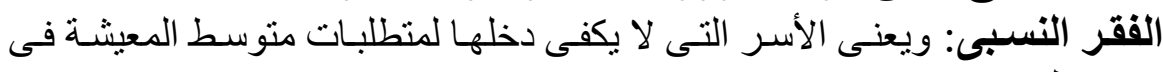
المجتمع.

الفقر فى الريف: يوجد هذا النوع فى المناطق قليلة السكان وتعتمد كل أسرة فيها

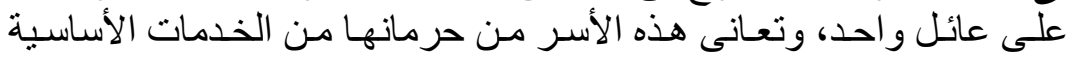

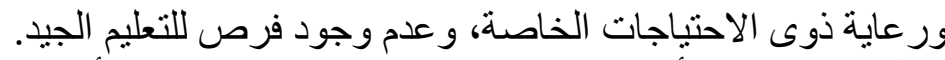

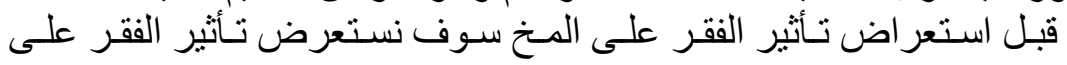

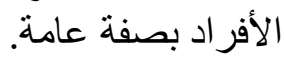

\section{تأثير الفقر على الأفراد:}

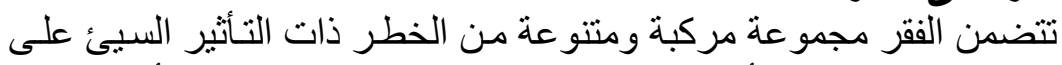

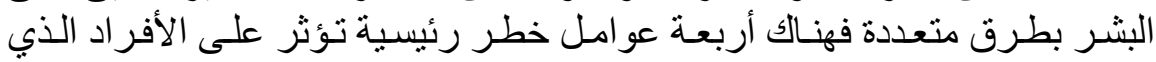

$$
\begin{aligned}
& \text { يعيشون فى فقر ، وهى: } \\
& \text { - تحديات إنفعالية واجتماعية. } \\
& \text { - ضغوط حادة ومزمنة. } \\
& \text { - - }
\end{aligned}
$$

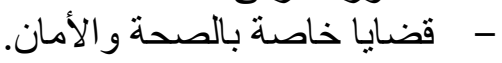

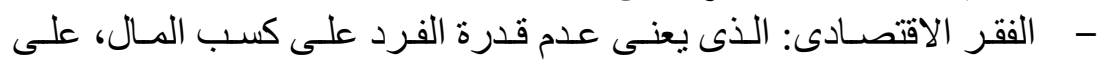

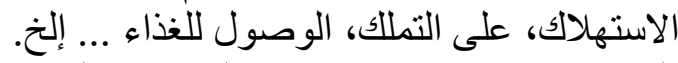

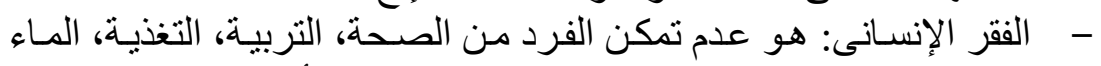

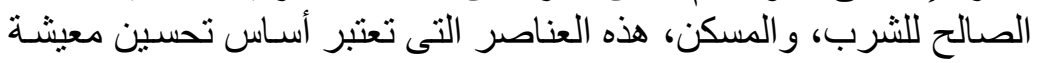

$$
\text { الفرد والوجود. }
$$

- - الفقر السياسي: يتجلى فلى غياب حقوق الإنسان، المشـاركة السياسية، هدر

$$
\text { الحريات الأساسية و الإنسانية. }
$$

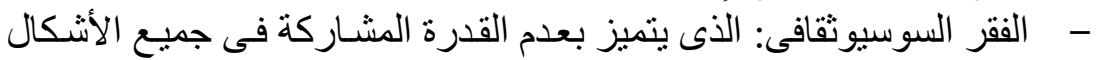

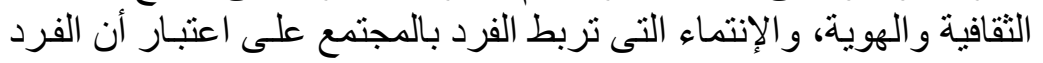

$$
\text { هو محور الجماعة والمجتمع. }
$$

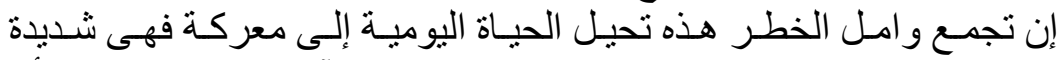

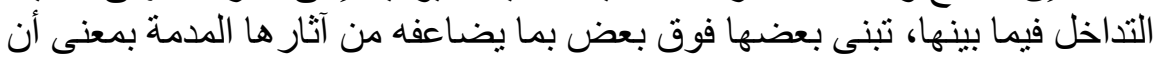

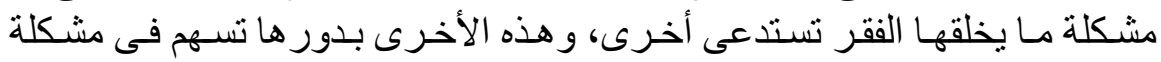

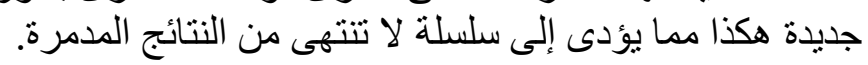

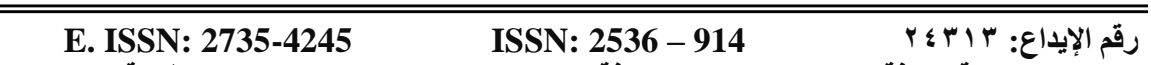
المجلة معرفة علي دوريات بنك المعرفة المصرى، و Edu Search دار المنظومة 


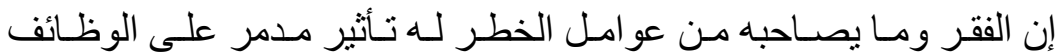

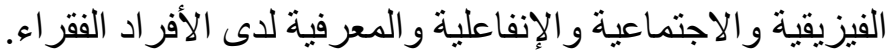

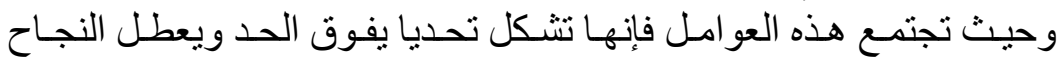

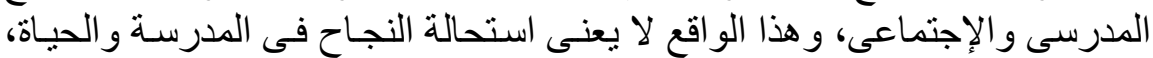

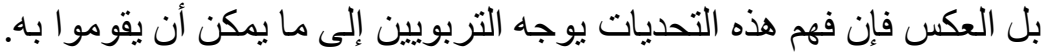

\section{السؤال كيف يصنع تلنى الموارد فى المنزل والأسرة والمدرسة.}

الأطفال الفقر اء فى حظر التحصيل المتدنى والفشـل فى إكمال التعليم حيـث

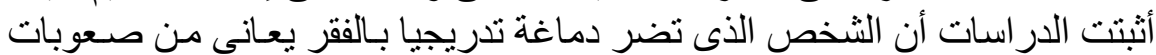

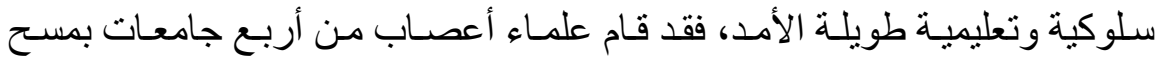

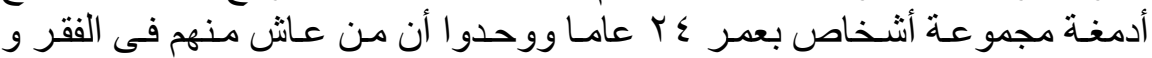

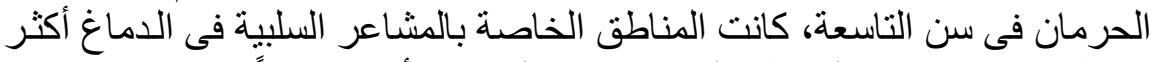
نشاطا من حين كانت المناطق التى تتبع هذه المشاعر أكثر هدو التهاً.

\section{الققر فى المنزل: - الم}

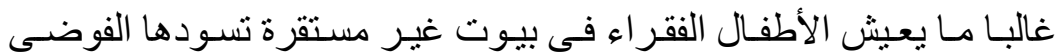

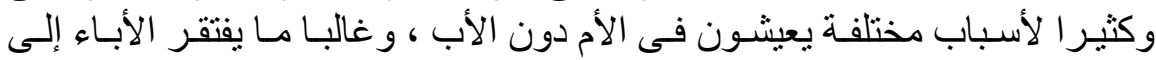

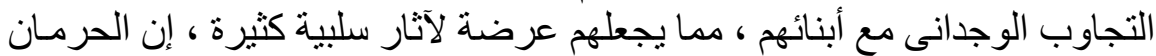

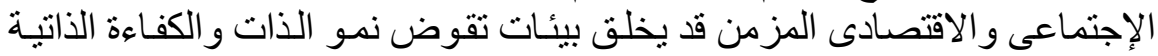

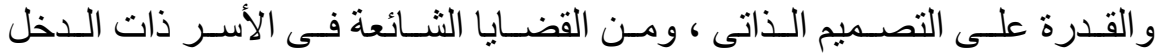

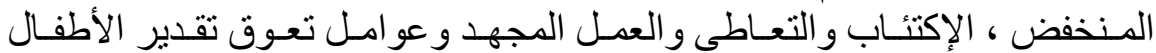

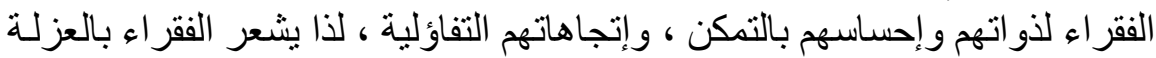

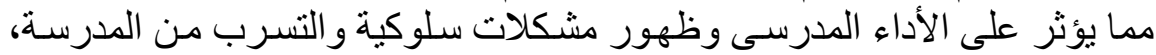

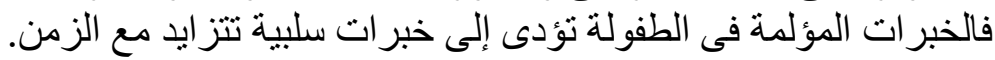

\section{الفقز فى المدرسة:}

تشـير الدر اسـات عن عو امسل الخطر إلى الارتبـاط الدال بين دخل الأسـرة

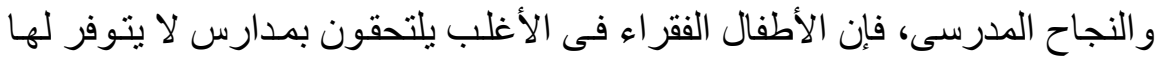

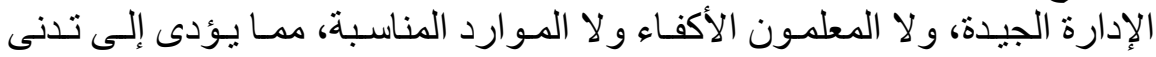

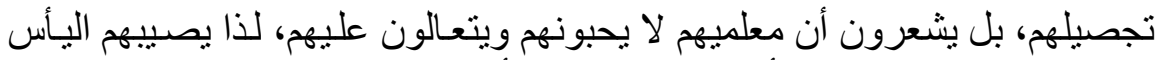

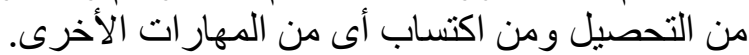

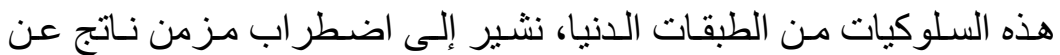
تعرض الطفل الدائم للضغوط.

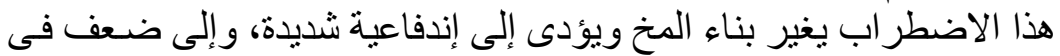

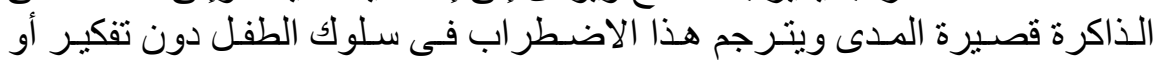
E. ISSN: 2735-4245
ISSN: 2536 - 914

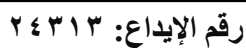
المجلة معرفة علي دوريات بنك المعرفة المصرى، و Edu Search دار المنظومة 
تحسب النتائج، هذه السلوكيات التى يبديها الأطفال الفقراء و همـا سلوكيات لا تقدر

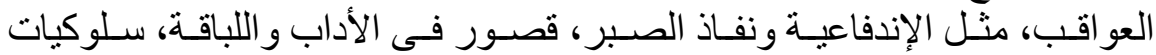

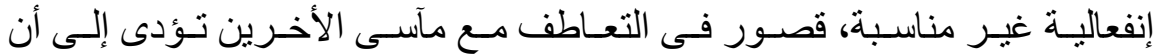
يتصرف الطفل دون وعى وينسى الخطو ات المهمة التى عليه إنجاز ها.

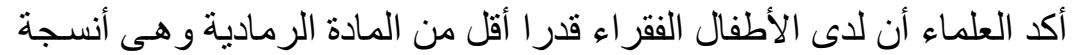

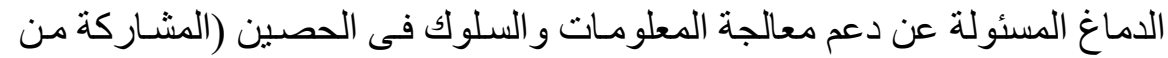
الذاكرة)، الفص الجبهى (المشارك فى اتخـاذ القرارات وحل المشكلات و السيطرة

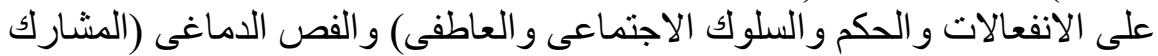

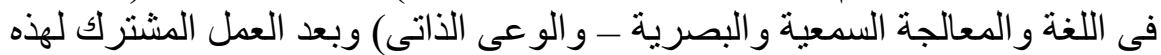

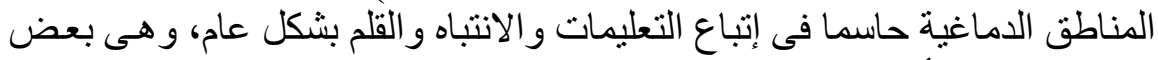

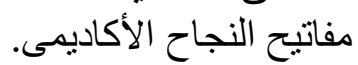
هذه السلوكيات التى يبديها الأطفال الفقر اء تنعكس على تعامل المعلم مـع

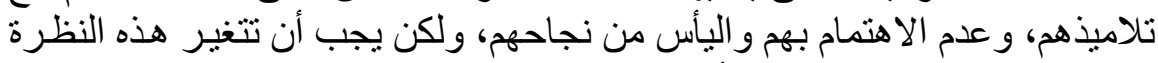

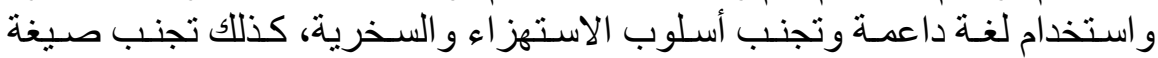

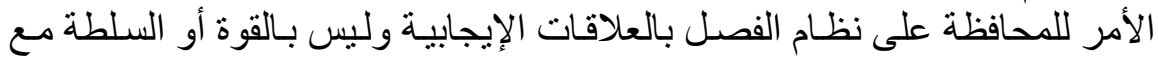

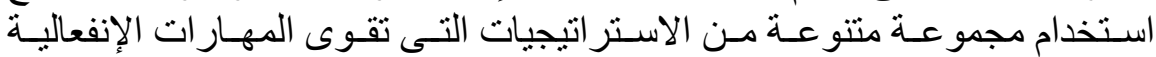
والإجتماعية.

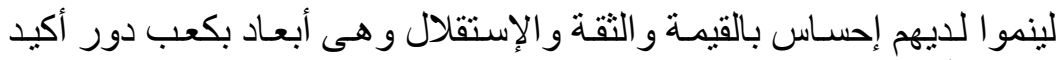
فى شخصية الأطفال للتغلب على الصورة المتكونة فى المخ.

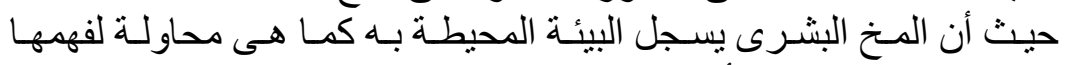
و استبعابها سو اء كانت إيجابية أو سلبية.

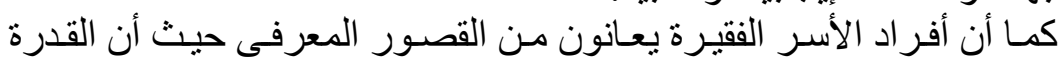

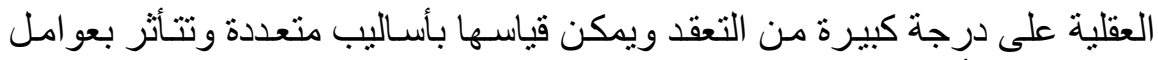

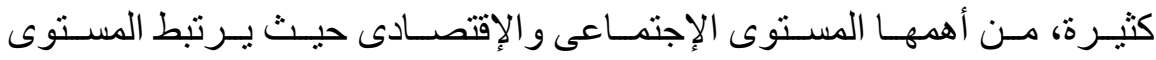

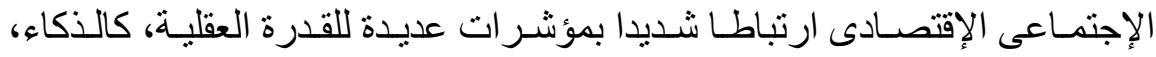

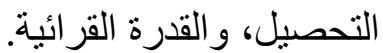

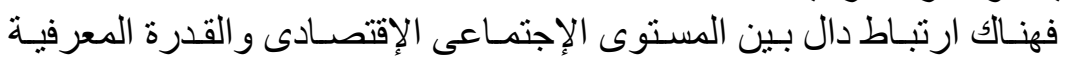
والأداء و هو ارتباط يستمر خلال مر احل النمو المختلفة.

\section{الققر وتأثيره على الأداء والسلولك:}

يتطلب الأداء المدرسى أن يستخدم المـخ مجمو عة من نظم عصبية معرفيـة

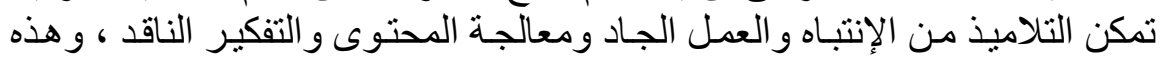

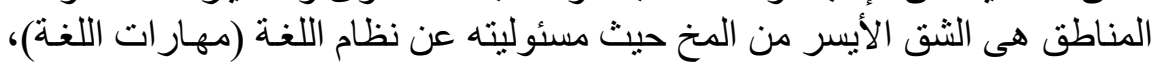

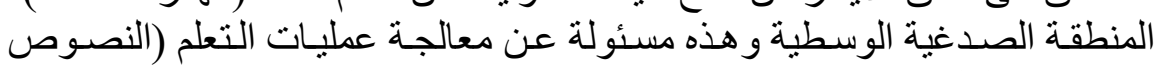

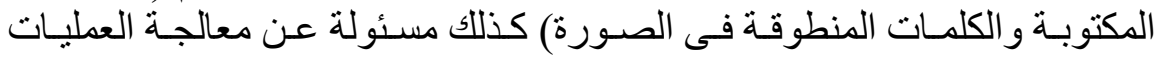

\footnotetext{
E. ISSN: 2735-4245

ISSN: 2536 - 914

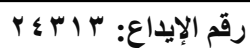

المجلة معرفة علي دوريات بنك المعرفة المصرى، و Edu Search دار المنظومة
} 
الإنفاعلية، المنطقة الجداريـة وهذه المنطقة مـن المـخ لها أهميـة خاصـة في التنظيم

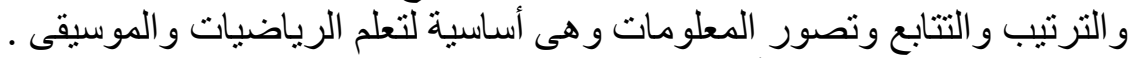

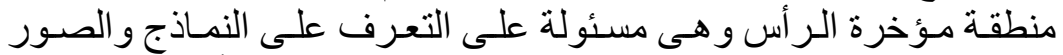

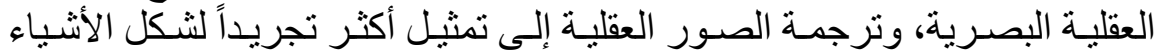

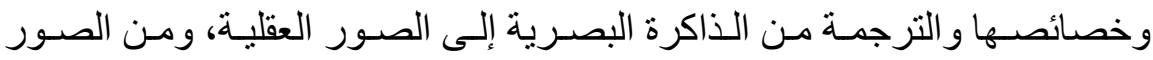
العقلية إلى الذاكرة البصرية وكان السؤال الذى يتكرر طرحه هل هل تم إجر اء مسح لمخ الأطفال في الأسر

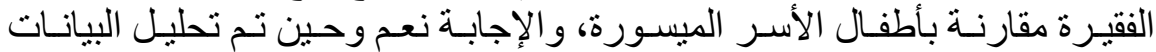

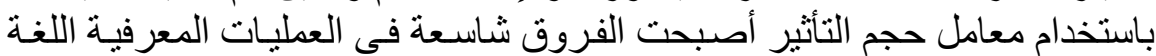

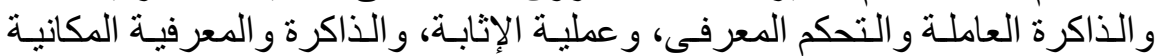
و المعرفة البصرية.

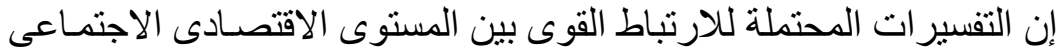

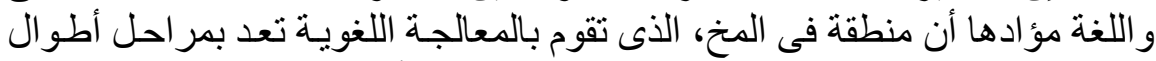
من غير ها من مناطق المخ حتى تتضـج ومن الممكن أن طول الفترة التى التى يتطلبها

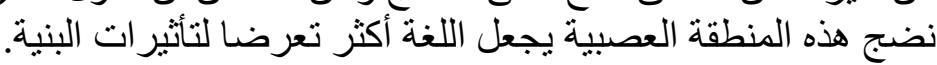

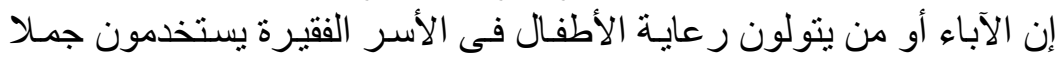
قصيرة، ذات تركيب نحوى بسيط، كذللك فالأسئلة من الآبـاء للأبنساء أو من الأبـاء الأبناء

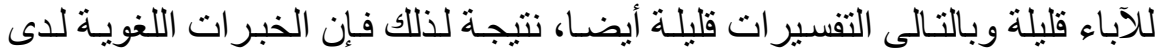

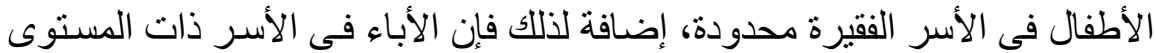

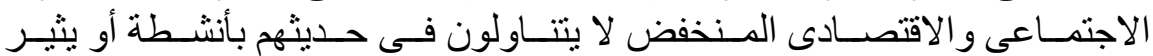
استجابات تتصف بالتأمل أو التمعن من جانب أطفالهم.

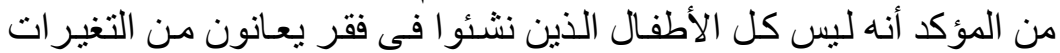

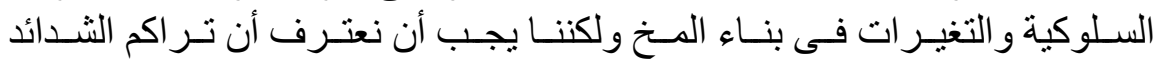

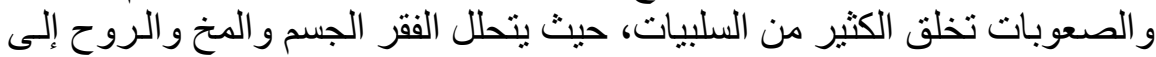

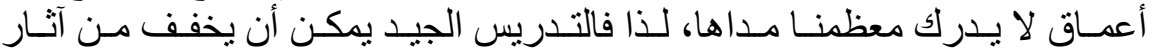

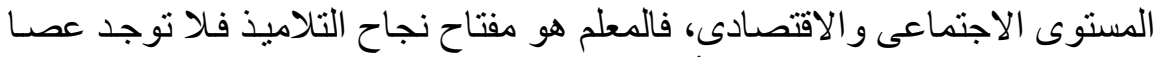

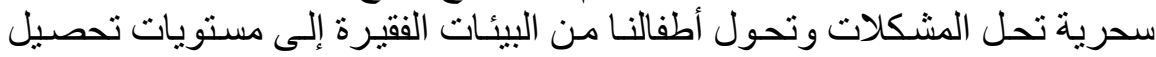
عليا ولكننا نستطيع أن نحقق الكثير بتو اصل الجهون الجهود.

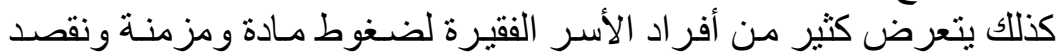

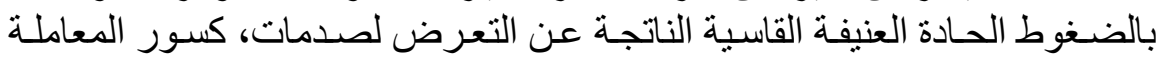

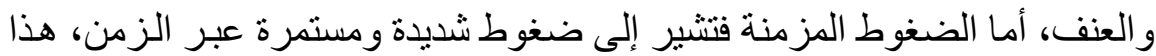

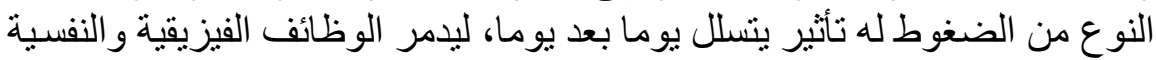

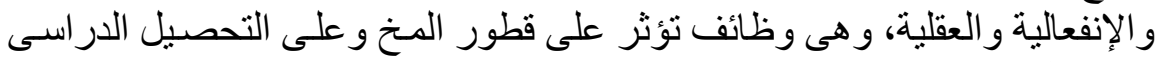
و على الكفاعة الاجتماعية. ولعية.

\footnotetext{
E. ISSN: $2735-4245$

ISSN: 2536 - 914

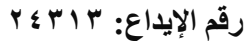

المجلة معرفة علي دوريات بنك المعرفة المصرى، و Edu Search دار المنظومة
} 


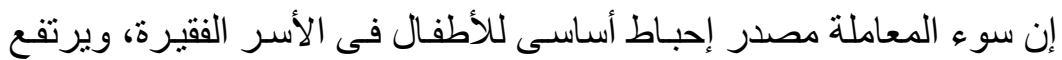

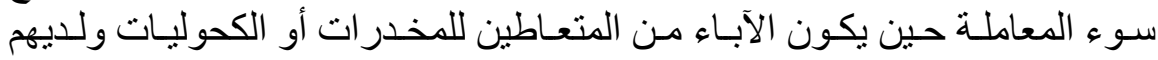

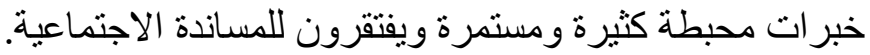

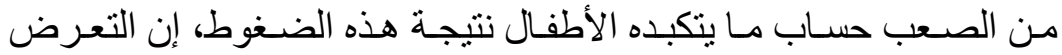

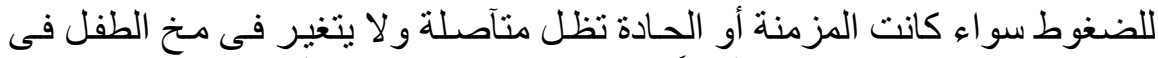

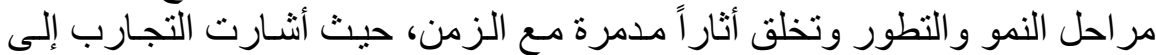

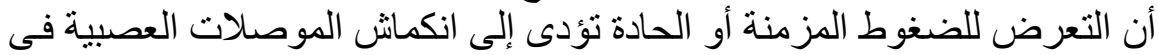

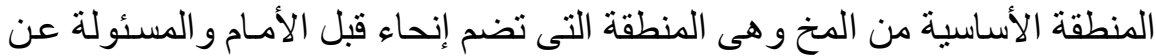

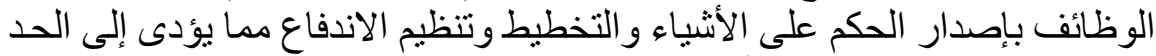

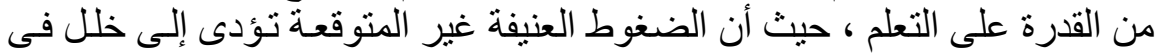

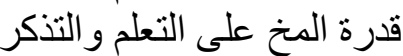

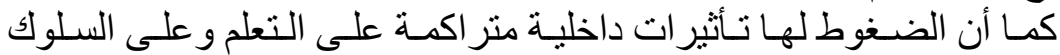

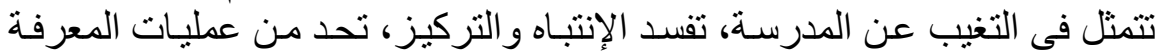

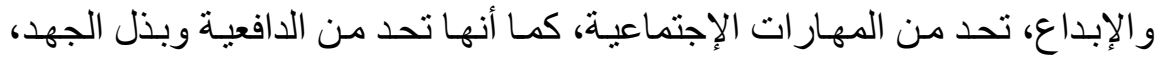
وتحد من نمو خلايا جديدة بالمخت.

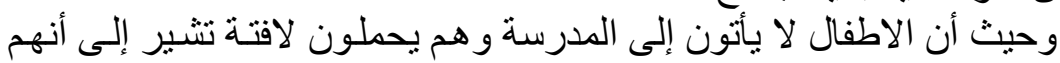

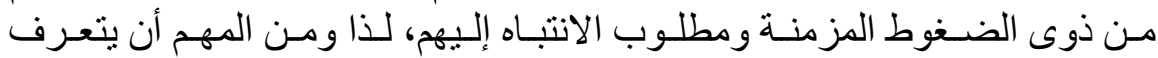

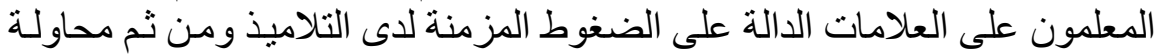

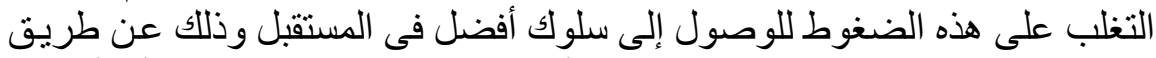

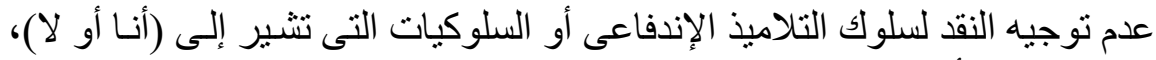

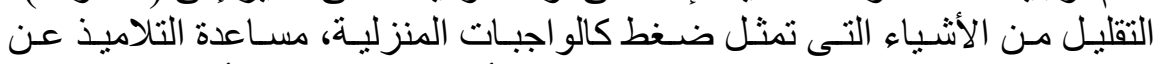

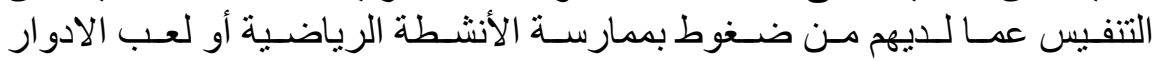

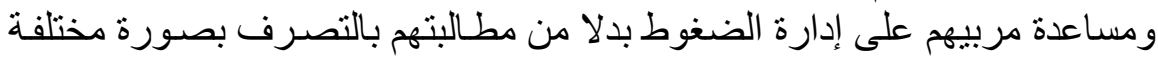

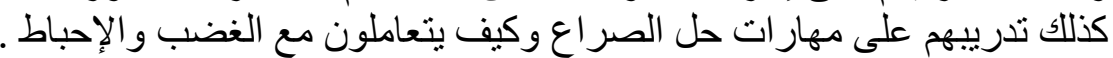

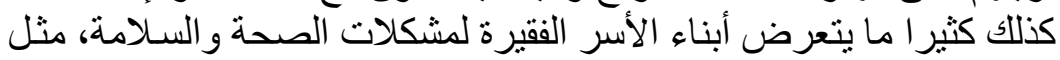

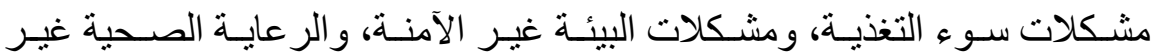

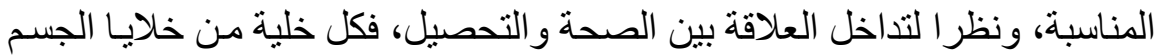

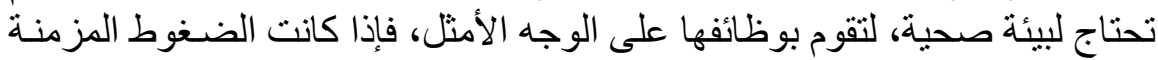

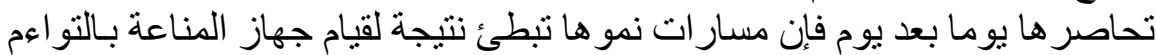

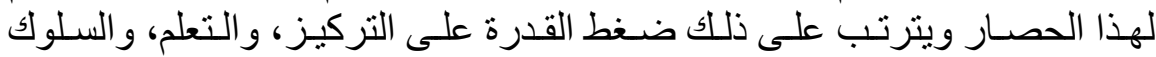

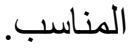

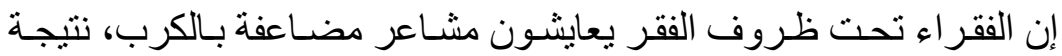

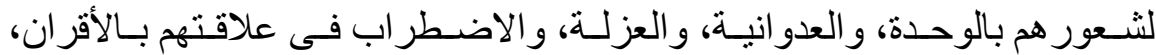

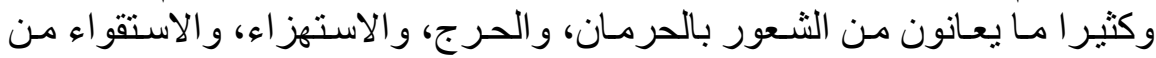
الآمرين نتيجة لذلك يواجهون مشكلات عديدة في حياتهم وينتقل هذا الثـعور إلى الى الثي

\footnotetext{
E. ISSN: 2735-4245

ISSN: 2536 - 914

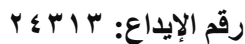

المجلة معرفة علي دوريات بنك المعرفة المصرى، و Edu Search دار المنظومة
} 
أطفالهم الذين يفقدون ثقتهم بأنفسه وبالغد مما يزيد من مخاطر إصسابتهم بـاختلالات

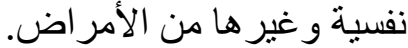

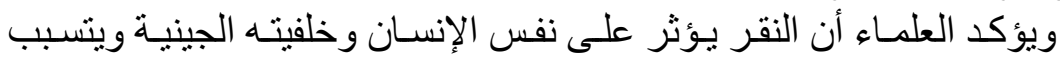

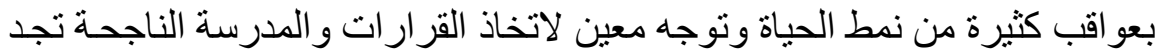

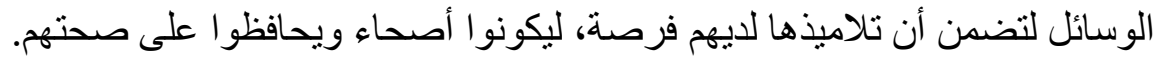

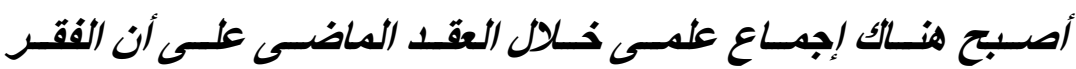

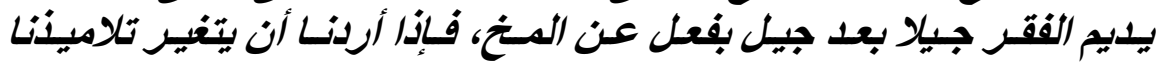

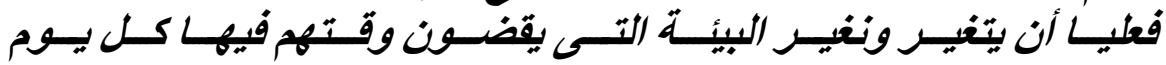

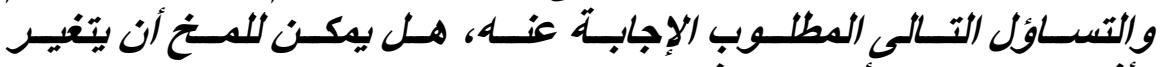

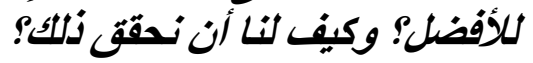

